\title{
Genome-wide association studies identify genetic loci for low von Willebrand factor levels
}

Janine van Loon, Abbas Dehghan, Tang Weihong, Stella Trompet, Wendy L McArdle, Folkert W Asselbergs, Ming-Huei Chen, Lorna M Lopez, Jennifer E Huffman, Frank WG Leebeek, Saonli Basu, David J Stott, Ann Rumley, Ron T Gansevoort, Gail Davies, James JF Wilson, Jacqueline CM Witteman, Xiting Cao, Anton JM de Craen, Stephan JL Bakker, Bruce M Psaty, John M Starr, Albert Hofman, J Wouter Jukema, Ian J Deary, Caroline Hayward, Pim van der Harst, Gordon DO Lowe, Aaron R Folsom, David P Strachan, Nicolas Smith, Moniek PM de Maat and Christopher O'Donnell

European Journal of Human Genetics (2016) 24, 1096; doi:10.1038/ejhg.2016.21

Correction to: European Journal of Human Genetics (2016) 24, 1035-1040;

doi:10.1038/ejhg.2015.222; published online 21 October 2015
This has now been rectified. The corrected paper also appears in this issue.

Post online publication it was realised that one of the author

names (Folkert W Asselbergs) had been submitted incorrectly.

\section{International Charter of principles for sharing bio-specimens and data}

Deborah Mascalzoni, Edward S Dove, Yaffa Rubinstein, Hugh JS Dawkins, Anna Kole, Pauline McCormack, Simon Woods, Olaf Riess, Franz Schaefer, Hanns Lochmüller, Bartha M Knoppers and Mats Hansson

European Journal of Human Genetics (2016) 24, 1096; doi:10.1038/ejhg.2015.237

Correction to: European Journal of Human Genetics (2015) 23, 721-728;

doi:10.1038/ejhg.2014.197; published online 24 September 2014
MRC Centre for Neuromuscular Diseases, Institute of Genetic Medicine, Newcastle University, Newcastle upon Tyne, UK.

The authors have requested that Hanns Lochmüller's affiliation be amended to: The John Walton Muscular Dystrophy Research Centre,

\section{Big Data in medical research and EU data protection law: challenges to the consent or anonymise approach}

Menno Mostert, Annelien L Bredenoord, Monique CIH Biesaart and Johannes JM van Delden European Journal of Human Genetics (2016) 24, 1096; doi:10.1038/ejhg.2016.71

Correction to: European Journal of Human Genetics (2016) 24, 956-960; doi:10.1038/ejhg.2015.239; published online 11 November 2015
This paper has been changed from 'Review' to 'Policy' since advance online publication. 